\title{
Neutropenia in primary immunodeficiency
}

\author{
Robert Sokolic \\ Disorders of Immunity Section, Genetics and Molecular Biology Branch, National Human \\ Genome Research Institute, National Institutes of Health, Bethesda, Maryland, USA
}

\section{Abstract}

Purpose of review-Neutropenia is a feature of several primary immunodeficiency diseases (PIDDs). Because of the diverse pathophysiologies of the PIDDs and the rarity of each disorder, data are often lacking, leading to the necessity of empiric treatment. Recent developments in the understanding of neutropenia in several of the PIDDs make a review of the data timely.

Recent findings-The category of severe congenital neutropenia continues to expand. Mutations in G6PC3 have been identified as the cause of neutropenia in a minority of previously molecularly undefined cases. Recent advances have broadened our understanding of the pathophysiology and the clinical expression of this disorder. A possible function of the C16orf57 gene has been hypothesized that may explain the clinical overlap between Clerucuzio-type poikiloderma with neutropenia and other marrow diseases. Plerixafor has been shown to be a potentially useful treatment in the warts, hypogammaglobulinemia, infection, and myelokathexis syndrome. Investigations of patients with adenosine deaminase deficient severe combined immunodeficiency have identified neutropenia, and particularly susceptibility to myelotoxins, as a feature of this disorder. Granulocyte-colony stimulating factor is the treatment of choice for neutropenia in PIDD, whereas hematopoietic cell transplantation is the only curative option.

Summary-The number of PIDDs associated with neutropenia has increased, as has our understanding of the range of phenotypes. Additional data and hypotheses have been generated helping to explain the diversity of presentations of neutropenia in PIDDs.

\section{Keywords}

granulocyte-colony stimulating factor; hematopoietic cell transplantation; neutropenia; primary immunodeficiency disorders

\section{INTRODUCTION}

The primary immunodeficiency diseases (PIDDs) include more than 150 different conditions [1-]. In the past 2 years, advances in this field have occurred in both myeloid and lymphoid immunodeficiencies. This review will address recent developments in these areas, with a

Correspondence to Robert Sokolic, MD, Staff Clinician, Disorders of Immunity Section, Genetics and Molecular Biology Branch, National Human Genome Research Institute, National Institutes of Health, 10 Center Drive, MSC 1611, Building 10CRC, Room 6-3330, Bethesda, MD 20892-1611, USA. Tel: +1 301451 1498; sokolicr@mail.nih.gov.

Conflicts of interest

There are no conflicts of interest. 
primary focus on entities that lead to neutropenia as an isolated finding or in the context of

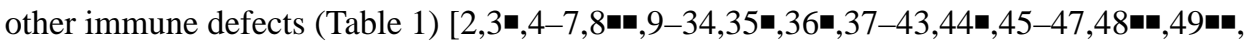
50-58], excluding marrow disorders presenting as pancytopenia and disorders only described in single patients or kindreds. Treatment of neutropenia in the setting of PIDD will also be discussed.

\section{GLUCOSE-6-PHOSPHATASE CATALYTIC UNIT 3 DEFICIENCY}

Glucose-6-phosphatase catalyzes the final steps of gluconeogenesis and glycogenolysis in the endoplasmic reticulum (ER). Three genes with this activity have been described, the most widely expressed of which is glucose-6-phosphatase catalytic unit 3 (G6PC3) [59,60]. Mutations in this gene were found to be a cause of severe congenital neutropenia in 2009 [7]. The neutrophils of patients with this disease, now known as severe congenital neutropenia type 4 (SCN4) [1- $]$, have an increased sensitivity to apoptosis. Associated findings include structural heart defects, urogenital abnormalities, and venous angiectasia. In the past 2 years, extensive work has been done to delineate both the pathophysiology and the range of phenotypes of this syndrome.

The first patients described with $G 6 P C 3$ deficiency had an absence of mature neutrophils in the marrow, consistent with early apoptosis. In 2010, McDermott et al. [9] published a variant form of the disease showing myelokathexis. The two patients reported in this article were homozygous for a missense mutation at nucleotide 778 of $G 6 P C 3$, coding for p.G260R. McDermott et al. reported decreased oxidase activity in their two patients, which was not identified in the original G6PC3-deficient cohort. Although the cohort of Boztug et al. [7] did include two patients with G260R, neither of these patients' bone marrows was assessed morphologically. Because of the finding of myelokathexis, McDermott et al. [9] examined the expression of CXCR4, the protein that is absent or mutated in warts, hypogammaglobulinemia, infection, and myelokathexis (WHIM) syndrome, in their patients and in G6pc3-knockout mice, finding it to be elevated in both cases. Treatment of the patients with granulocyte-colony stimulating factor (G-CSF) led to a decrease in CXCR4 expression along with an increase in absolute neutrophil count (ANC). Further tying the increased expression of CXCR4 to the patients' neutropenia, plerixafor, a specific CXCR4 antagonist, mobilized neutrophils into the circulation of G6pc3-knockout mice.

Neutropenia with G6PC3 mutations was further described in 2011 by a British-Israeli team [61-]. All four reported patients were members of a single kindred of Palestinian citizens of Israel and shared the same missense mutation as the first family reported by Boztug et al. [7], c.758G >A leading to p.R253H. Three of the patients in this report were in their third decade, all older than the patients of Boztug et al. [7]. Consequently, Banka et al. [61-] describe their patients as representing the adult phenotype of SCN4. This phenotype includes venous varicosities and stasis ulcers, growth delay and small adult size, developmental delay or learning disabilities, and delayed sexual maturation in two of the three adult patients. The extent to which these findings represent the true adult phenotype of G6PC3 mutation versus coinherited phenotypes in this highly consanguineous family is not clear, although venous varicosities and stasis ulcers could be related to the venous ectasia described by Boztug et al. The description of this phenotype may have important clinical 
implications for patients with G6PC3 mutations, because stasis ulcers would represent a substantial clinical problem in the setting of neutropenia.

Although not commented upon by the authors, the ANCs of the Palestinian patients reported by Banka et al. [61-] appear to be higher than those of the Aramean patients with the same mutation reported by Boztug et al. [7]. In the earlier paper, two out of five patients never had ANCs above 100 cells/ $\mu \mathrm{l}$, whereas the lowest ANC reported by the Israeli-British team was 200 cells $/ \mu 1$. The youngest patient was able to mount an ANC of 7700 cells $/ \mu l$, although under what clinical circumstances is not clear. Banka et al. do not mention the extent to which their patients were treated with G-CSF, and if they do have higher neutrophil counts than the patients of Boztug et al. they may not be cytokine-dependent. This difference may be explained by other genomic factors, or it could represent the variability of the newly described disease.

Gatti et al. [62] presented a case report of the first South American patient with G6PC3 deficiency in 2011. The mutation was a two base pair deletion leading to a frameshift. The child had lived 10 years without diagnosis or treatment. Between infections, the ANC could rise above 1000 cells $/ \mu$. The marrow showed a lack of mature neutrophils and was otherwise described as nonspecific.

Despite an apparently benign bone marrow examination, the patient had neutropenia below 200 cells/ $\mu 1$, anemia with reticulocytopenia, and thrombocytopenia. The two patients of McDermott et al. [9] were said to have iron deficiency anemia. In the report of Banka et al. [61-], all four patients are said to be anemic, but reticulocyte counts or further evaluation are not mentioned, and patient number 1 appears to be persistently thrombocytopenic. Boztug et al. [7] mention mild thrombocytopenia in one of their patients, but otherwise do not describe findings in red cells or platelets in their initial report. The contribution of either inflammation or iron deficiency to the South American patient's anemia is not clear. Moreover, he was found to have antierythrovirus B19 IgM antibodies a month after the initial laboratory values were obtained. Nevertheless, it appears that patients with G6PC3 deficiency may manifest cytopenias beyond simply neutropenia. The patient of Gatti et al. [62] could be maintained on a low dose of G-CSF, $1.8 \mu \mathrm{g} / \mathrm{kg} / \mathrm{day}$. This, coupled with the patient's survival without treatment to age 10, may suggest that his mutation, despite being a frameshift, resulted in milder disease than that of some of the other patients described.

Boztug et al. [8-1] have more recently revisited the question of the G6PC3-deficient phenotype. Of 31 patients studied, 16 had homozygous or compound heterozygous mutations of G6PC3. Ten of these 16 had intermittent thrombocytopenia. The most common nonhematologic manifestation was venous ectasia, present in 14 of the 16 patients. Four patients had homozygous frameshift mutations, although there was no comment on their clinical course being better or worse than average. Fifteen of the 16 patients were maintained on G-CSF, with doses averaging $3.3 \mu \mathrm{g} / \mathrm{kg} / \mathrm{day}$, and ranging from 0.7 to $14 \mu \mathrm{g} / \mathrm{kg} / \mathrm{day}$. Twelve of the 15 used G-CSF less than once per day. In almost three centuries of cumulative follow-up, no patient developed leukemia, and this was found to be statistically different from an SCN cohort of 374 patients. No patient had myelokathexis. In some patients, the 
authors noted an SCN4 phenotype without mutations in the coding region of G6PC3, suggesting that other genes may be involved in SCN4.

Three recent articles have investigated the pathophysiology of the G6PC3 deficiency. Using a knockout mouse model [63], Jun et al. [64] showed that glucose transport out of the ER is deficient in neutrophils of $G 6 p c 3-/-$ mice and $G 6 P C 3-/-$ humans. Biochemical results of this deficiency included decreased glucose-6-phosphate in neutrophil cytoplasm, decreased lactate, and decreased ATP. In the murine model, neutrophils had decreased levels of the phagocyte oxidase proteins and inhibited oxidative burst, chemotaxis, and phagocytosis. In this respect, the knockout mice differ from the first kindred presented by Boztug et al. [7], who were homozygous for a missense mutation and had apparently normal neutrophil function. Recently, Jun et al. [65-] showed that the neutrophil dysfunction of G6pc3knockout mice is ameliorated by G-CSF. Because McDermott et al. [9] had shown decreased respiratory burst activity in humans with $G 6 P C 3$ deficiency, this finding may have clinical importance.

Hayee et al. [66"] showed a diffuse decrease in glycosylation in patients with G6PC3 deficiency or with glycogen storage disease Ib/glucose-6-phosphate translocase (G6PT) deficiency. G6PT forms a complex with G6PC3 in the ER, where the former protein translocates glucose-6-phosphate from the cytoplasm, and the latter dephosphorylates the substrate. Given this profound glycomic disorder, the authors classify both diseases among the congenital disorders of glycosylation.

\section{POIKILODERMA WITH NEUTROPENIA}

In 2010, an Italian family with Clericuzio-type poikiloderma with neutropenia was found to have a mutation in C16orf57 [67]. At that time, the gene's function was unknown. In 2012, Colombo et al. [68] reported on two novel C16orf57mutations. Further work in silico led the authors to hypothesize that $C 16$ orf 57 functions in RNA processing. If this hypothesis is correct, it could provide a pathophysiologic basis for the clinical overlap of poikiloderma with neutropenia, with dyskeratosis congenita with normal telomere length, and with Rothmund-Thomson syndrome [69].

\section{NEUTROPENIA IN DISORDERS OF CXCL12/CXCR4 SIGNALING}

The CXCR4 receptor is hyperfunctional in WHIM syndrome [70]. Based on the understanding of the molecular etiology of this disease as a gain-of-function mutation in CXCR4 [71], McDermott et al. [72-] demonstrated that the CXCR4 antagonist plerixafor could counteract this hyperfunctionality. In 2011, the same authors [49-1] and a separate group [48-] showed that plerixafor could be used to increase neutrophil, lymphocyte, and monocyte counts in patients with WHIM syndrome. Both studies were dose escalation studies, showing an effective dose well below the dose approved by the US Food and Drug Administration for mobilizing peripheral blood hematopoietic stem cells, $0.24 \mathrm{mg} / \mathrm{kg}$. In their report, the group from the National Institute of Allergy and Infectious Diseases discuss the potential for unintended consequences of chronic complete blockage of CXCR4, noting the knockout mice to be nonviable. The authors claim to have only partially blocked 
CXCR4, estimating that at the lowest dose only about $30 \%$ of CXCR4 receptors were blocked. The data upon which this estimate is based are not presented. For this reason, and because the appropriate dose and schedule of plerixafor in WHIM syndrome have not been determined, G-CSF remains the treatment of choice [73].

In 2012, Liu et al. [74-] presented the first case of WHIM syndrome caused by a point mutation in $C X C R 4$, c.1027G->A, coding for p.343E->K. All previous reports of WHIM syndrome due to $C X C R 4$ mutations had been of truncating mutations. As is the case for truncated proteins, McDermott et al. found the missense mutation to cause CXCR4 to be hyperfunctional.

A potential second immunodeficiency involving CXCR4 and CXCL12 was identified in 2011 [75-]. The reported patients had neutropenia, hypogammaglobulinemia, and recalcitrant warts, but did not have myelokathexis. Both patients had B-cell and natural killer cell lymphopenia, which is not typically associated with WHIM syndrome. Furthermore, no mutations in the $C X C R 4$ gene were identified. The patients' lymphocytes had reduced internalization of CXCR4 when stimulated with CXCL12, a finding which the authors had previously demonstrated in patients with WHIM syndrome [76].

\section{NEUTROPENIA IN COMBINED IMMUNODEFICIENCY}

In addition to the primary neutropenic immunodeficiencies, neutropenia can be found as a feature of what are primarily thought of as lymphoid immune deficiencies, including several subtypes of combined immunodeficiency (Table 1).

Recent work has shown a predisposition to neutropenia among children with adenosine deaminase deficient severe combined immunodeficiency (ADA-SCID). This was fist identified in a trial of gene therapy [77], wherein two out of 10 patients had prolonged neutropenia after receiving $4 \mathrm{mg} / \mathrm{kg}$ of busulfan, less than half of the myeloablative dose [78]. A previous observation reported prolonged pancytopenia after a similar low dose of busulfan in a single patient [79]. Complicating the interpretation of this severe adverse event was a finding of a minority population of cells with trisomy 8 in marrow of the patient stored before gene therapy.

Our recent findings in a cohort of 13 patients with ADA-SCID further describe neutropenia in this condition [29]. Although none of the patients were profoundly neutropenic at the time of description, all of the patients had morphologic abnormalities of myeloid cells in the peripheral blood (Fig. 1), and of the six whose marrow was studied, all were found to have cytologic dysplasia. As was seen in two of the patients of Aiuti et al. [77], we observed prolonged neutropenia after low-dose busulfan given as conditioning prior to gene therapy for ADA-SCID. All three of the patients who received busulfan ultimately were treated with G-CSF in order to achieve a sustained ANC greater than 500 cells/ $\mu$ l. Additional findings included susceptibility to drug-induced neutropenia and an inverse correlation between ANC and deoxyadenosine metabolite percentage, a marker of metabolic burden of disease in ADA-SCID, at diagnosis. 
Although these reports raise the suspicion of neutropenia as a feature of ADA-SCID, it is unclear whether this finding is a genuine manifestation of ADA deficiency, or whether it could be fully explained as an exaggerated response to myelotoxins, rather than an inherent myeloid abnormality. On the basis of our more recent findings, it can be argued that neutropenia is in fact a primary manifestation of ADA deficiency. We have made preliminary observations in two patients who became mixed chimeras after either allogeneic hematopoietic cell transplantation (HCT) or gene therapy for ADA-SCID [80]. In both cases, withdrawal of pegylated adenosine deaminase (PEG-ADA) months to years after cellular therapy led to an increase in the percentage of ADA-expressing lymphocytes. PEGADA withdrawal was accompanied by an expected increase and then fall of deoxyadenosine metabolites, during which neutropenia was observed. As metabolic control was regained with selection of ADA-expressing cells, the neutropenia improved. The patient who had had allogeneic HCT had 89\% T-cell chimerism prior to PEG-ADA withdrawal. He had a transient neutropenia, whereas the gene therapy patient, who had $1 \%$ marking prior to PEGADA withdrawal, required prolonged administration of G-CSF before being able to maintain an ANC above 500 cells/ $\mu$ l. Before discontinuing the drug, the second patient used G-CSF as infrequently as once every 14 days.

Two groups described a new molecular etiology of combined immunodeficiency in April of 2012 [35-,36]. The patients studied by Abdollahpour et al. [35-] were three members of a single Iranian family with stop mutations due to a single nucleotide substitution in exon 7 of STK4, also known as MST1, a gene whose product has antiapoptotic activity. In addition to deficiencies of B and T cell numbers, all three patients had neutropenia. Infections were both bacterial and viral. T cells and neutrophils showed increased apoptosis. Although these patients presented between ages 2 and 10, and were able to make specific antibodies against tetanus and diphtheria toxoids, two other members of the kindred died from sepsis in infancy.

Nehme et al. [36-] presented four Turkish patients from two consanguineous marriages with mutations in STK4. All patients had viral and bacterial infections, neutropenia, and autoimmunity. T-cell function was also impaired. Patients had elevated levels of $\operatorname{IgG}$ and $\operatorname{IgA}$ and made antibodies to polio, but not to tetanus or diphtheria toxoids, or to Haemophilus influenzae or Streptococcus pneumoniae. The authors characterized the syndrome as combined immunodeficiency rather than SCID. All four patients had truncating mutations of STK4. Additional findings included a decreased amount of IL7Ra, a protein absent in a minority of autosomal recessive SCID patients. Two patients died after alternative donor $\mathrm{HCT}$, and one was cured by the procedure.

\section{TREATMENT OF NEUTROPENIA IN PRIMARY IMMUNODEFICIENCY DISEASE}

Febrile neutropenia is a medical emergency in all cases. Although outpatient treatment with oral antibiotics has been advocated for low-risk patients expected to recover their white counts after cancer chemotherapy [81], the data for such an approach do not exist for neutropenia in PIDD, and this strategy cannot be recommended. Appropriate management 
consists of empiric broad-spectrum antibiotics administered in an inpatient setting. As in postchemotherapy neutropenia, localizing signs and symptoms may be lacking in neutropenic patients with PIDD. However, unlike the case with postchemotherapy neutropenia, patients with PIDD and neutropenia are often able to increase their ANC in the face of an infectious challenge. Although this may make the outcomes of febrile neutropenia in PIDD less severe than in the post-chemotherapy setting, data for this hypothesis are lacking. Furthermore, patients with postchemotherapy neutropenia can be expected to recover their counts in a few days, whereas patients with neutropenic PIDD will not. The original data supporting empiric antibiotics for febrile neutropenia come from the postchemotherapy setting [82], and, in the absence of data specific to PIDD, it seems appropriate to extrapolate from these data in making treatment decisions.

Beyond the acute setting, treatment of neutropenia in PIDD depends on the underlying disorder, the overall health of the patient, and the goals of the patient and family. In the precytokine era, patients with irreversible neutropenia who were not cured by HCT could be given prophylactic antibiotics. Although this approach is still advocated by some experts [13], it is not universally recommended [83- $]$, and other authors cite G-CSF as the treatment of choice for neutropenia in PIDD [45,53]. In the case of autoimmune neutropenia in humoral or combined immunodeficiencies, consideration can be given to corticosteroid treatment, although this must be done with caution in patients with PIDD and severe neutropenia. Alternative treatments include immunoglobulin replacement, G-CSF [84], and rituximab or alemtuzumab [46].

For the primary neutropenic disorders, G-CSF is the treatment of choice in the absence of curative HCT [83-m]. This treatment has reduced infectious morbidity [85] and mortality [86]. Although only 5\% of patients with SCN have no response to G-CSF [87], the amount of cytokine needed varies greatly from less than 5 to $120 \mu \mathrm{g} / \mathrm{kg} / \mathrm{day}$. Those patients who do not respond to $120 \mu \mathrm{g} / \mathrm{kg} / \mathrm{day}$ of G-CSF are unlikely to respond to higher doses [88] and are appropriate candidates for HCT. Included among this group are patients with a constitutive extracellular G-CSFR mutation [14,89,90], who are absolutely refractory to G-CSF. Patients who require more than $8 \mu \mathrm{g} / \mathrm{kg} / \mathrm{day}$ of G-CSF have an increased risk for leukemic transformation [86].

The use of pegfilgrastim instead of filgrastim is theoretically attractive, and has been tried in isolated cases [91-94], but has not been routinely accepted, and may in fact lead to an increase in adverse events $[95,96]$. One obstacle to the use of this agent in the United States is the packaging of the commercially available product in a syringe prefilled with the adult dose of $6 \mathrm{mg}$. This would require either intentional overdosing or the cumbersome prospect of pharmacist re-packaging of the medicine if pegfilgrastim were used for children.

The experience of our group with neutropenia in ADA-SCID has been more variable. G-CSF is typically only needed after myelotoxic challenges, such as chemotherapy or myelotoxic drugs, and then only for a few weeks [29]. Antineutrophil antibodies have been found in several patients with ADA-SCID; however, the usual caveats of serologic diagnosis in patients on immunoglobulin replacement, as well as the known concerns about the poor specificity of the antineutrophil antibody assays, apply. There is no reported experience of 
the use of immunosuppression in this situation. The utility of PEG-ADA to treat the neutropenia of ADA-SCID is not clear.

For most PIDDs, the only curative treatment is allogeneic HCT [97,98]. Although this procedure is clearly indicated in SCID [99m], with the possible exception of ADA-SCID without a matched related donor [100], it is more selectively applied in other PIDDs (Table 1). PIDDs with neutropenia in which HCT is generally considered to potentially have a favorable risk-benefit ratio include, in addition to SCID, X-linked hyper-IgM syndrome (CD40L deficiency), Chediak-Higashi syndrome, Griscelli syndrome, severe congenital neutropenia, and cyclic neutropenia [97].

Finally, genetically modified autologous HCT has been used as an investigational modality in several PIDDs [101-107], with notable successes in SCID, chronic granulomatous disease, and Wiskott-Aldrich syndrome. Gene therapy remains a potentially useful modality for PIDDs with neutropenia, but is still at the preclinical stage for most of them. Even in those disorders in which gene therapy has been carried out, its application must be judicious, given the potential for life-threatening or fatal adverse events [108-110] (and, press release from Hannover Medical School, http://www.asgct.org/UserFiles/file/ Genetherapy_WAS_final_english.pdf, accessed 1 August 2012).

\section{CONCLUSION}

Neutropenia is a feature of several myeloid and lymphoid PIDDs. The many different pathophysiologies represented by the PIDDs lend themselves to, and in fact necessitate, a more diversified and nuanced treatment approach than the standard used for febrile neutropenia after cancer chemotherapy. Additional clinical observations and investigations into both the pathophysiology and the management of neutropenia in the different PIDDs, as an isolated complication and in the context of the underlying disease, are required and can be expected. Until such new data are presented, the management of neutropenia in PIDDs will require a flexible, empiric, and patient-centered approach based on the use of cytokines and HCT with consideration of antibiotic prophylaxis and gene therapy in the appropriate settings.

\section{Acknowledgments}

The author would like to thank Drs Sergio Rosenzweig and Fabio Candotti for their thoughtful suggestions and review of the article. The intramural research program of the National Human Genome Research Institute funded this work.

\section{REFERENCES AND RECOMMENDED READING}

Papers of particular interest, published within the annual period of review, have been highlighted as:

- of special interest

- of outstanding interest

Additional references related to this topic can also be found in the Current World Literature section in this issue (pp. 72-73). 
1. Al-Herz W, Bousfiha A, Casanova J-L, et al. Primary immunodeficiency diseases: an update on the Classification from the International Union of Immunological Societies Expert Committee for Primary Immunodeficiency. Front Immunol. 2011; 2:1-26. [PubMed: 22566792] This is the most recent classification of the PIDDs by the International Union of Immunological Societies.

2. Zeidler C, Germeshausen M, Klein C, Welte K. Clinical implications of ELA2-, HAX1-, and GCSF-receptor (CSF3R) mutations in severe congenital neutropenia. Br J Haematol. 2009; 144:459_ 467. [PubMed: 19120359]

3. Carlsson G, Fasth A, Berglöf E, et al. Incidence of severe congenital neutropenia in Sweden and risk of evolution to myelodysplastic syndrome/leukaemia. Br J Haematol. 2012; 158:363-369.

[PubMed: 22624626] This is the first published report of SCN incidence, showing an incidence of about 1/100 000 in Sweden. This study confirms the high rate of leukemic transformation in this population.

4. Ferry C, Ouachee M, Leblanc T, et al. Hematopoietic stem cell transplantation in severe congenital neutropenia: experience of the French SCN register. Bone Marrow Transplant. 2005; 35:45-50. [PubMed: 15489867]

5. Donini M, Fontana S, Savoldi G, et al. G-CSF treatment of severe congenital neutropenia reverses neutropenia but does not correct the underlying functional deficiency of the neutrophil in defending against microorganisms. Blood. 2007; 109:4716-4723. [PubMed: 17311988]

6. Klein C, Grudzien M, Appaswamy G, et al. HAX1 deficiency causes autosomal recessive severe congenital neutropenia (Kostmann disease). Nat Genet. 2007; 39:86-92. [PubMed: 17187068]

7. Boztug K, Appaswamy G, Ashikov A, et al. A syndrome with congenital neutropenia and mutations in G6PC3. N Engl J Med. 2009; 360:32-43. [PubMed: 19118303]

8. Boztug K, Rosenberg PS, Dorda M, et al. Extended spectrum of human glucose-6-phosphatase catalytic subunit 3 deficiency: novel genotypes and phenotypic variability in severe congenital neutropenia. J Pediatr. 2012; 160:679-683. e672. [PubMed: 22050868] In this study, the authors further detail the phenotype of SCN4, particularly with respect to extrahematologic manifestations.

9. McDermott DH, De Ravin SS, Jun HS, et al. Severe congenital neutropenia resulting from G6PC3 deficiency with increased neutrophil CXCR4 expression and myelokathexis. Blood. 2010; 116:2793-2802. [PubMed: 20616219]

10. Person RE, Li FQ, Duan Z, et al. Mutations in proto-oncogene GFI1 cause human neutropenia and target ELA2. Nat Genet. 2003; 34:308-312. [PubMed: 12778173]

11. Khandanpour C, Thiede C, Valk PJ, et al. A variant allele of growth factor independence 1 (GFII) is associated with acute myeloid leukemia. Blood. 2010; 115:2462-2472. [PubMed: 20075157]

12. Huang M, Hu Z, Chang W. The growth factor independence-1 (Gfil) is overexpressed in chronic myelogenous leukemia. Acta Haematol. 2010; 123:1-5. [PubMed: 19887785]

13. Donadieu J, Fenneteau O, Beaupain B, et al. Congenital neutropenia: diagnosis, molecular bases and patient management. Orphanet J Rare Dis. 2011; 6:26. [PubMed: 21595885]

14. Sinha S, Zhu QS, Romero G, Corey SJ. Deletional mutation of the external domain of the human granulocyte colony-stimulating factor receptor in a patient with severe chronic neutropenia refractory to granulocyte colony-stimulating factor. J Pediatr Hematol/Oncol. 2003; 25:791-796.

15. Dale DC, Bolyard AA, Aprikyan A. Cyclic neutropenia. Semin Hematol. 2002; 39:89-94. [PubMed: 11957190]

16. Dale DC, Cottle TE, Fier CJ, et al. Severe chronic neutropenia: treatment and follow-up of patients in the Severe Chronic Neutropenia International Registry. Am J Hematol. 2003; 72:82-93. [PubMed: 12555210]

17. Ancliff PJ, Blundell MP, Cory GO, et al. Two novel activating mutations in the Wiskott-Aldrich syndrome protein result in congenital neutropenia. Blood. 2006; 108:2182-2189. [PubMed: 16804117]

18. Beel K, Vandenberghe P. G-CSF receptor (CSF3R) mutations in X-linked neutropenia evolving to acute myeloid leukemia or myelodysplasia. Haematologica. 2009; 94:1449-1452. [PubMed: 19794089]

19. Devriendt K, Kim AS, Mathijs G, et al. Constitutively activating mutation in WASP causes Xlinked severe congenital neutropenia. Nat Genet. 2001; 27:313-317. [PubMed: 11242115] 
20. Ochs HD. Mutations of the Wiskott-Aldrich syndrome protein affect protein expression and dictate the clinical phenotypes. Immunol Res. 2009; 44:84-88. [PubMed: 19082760]

21. Bouma G, Doffinger R, Patel SY, et al. Impaired neutrophil migration and phagocytosis in IRAK-4 deficiency. Br J Haematol. 2009; 147:153-156. [PubMed: 19663824]

22. Singh A, Zarember KA, Kuhns DB, Gallin JI. Impaired priming and activation of the neutrophil NADPH oxidase in patients with IRAK4 or NEMO deficiency. J Immunol. 2009; 182:6410-6417. [PubMed: 19414794]

23. Baldus M, Zunftmeister V, Geibel-Werle G, et al. Chediak-Higashi-Steinbrinck syndrome (CHS) in a 27-year-old woman: effects of G-CSF treatment. Ann Hematol. 1999; 78:321-327. [PubMed: 10466444]

24. Gennery AR, Slatter MA, Grandin L, et al. Transplantation of hematopoietic stem cells and longterm survival for primary immunodeficiencies in Europe: entering a new century, do we do better? J Allergy Clin Immunol. 2010; 126:602.e11-610.e11. [PubMed: 20673987]

25. Introne W, Boissy RE, Gahl WA. Clinical, molecular, and cell biological aspects of ChediakHigashi syndrome. Mol Gen Metab. 1999; 68:283-303.

26. Wenham M, Grieve S, Cummins M, et al. Two patients with Hermansky Pudlak syndrome type 2 and novel mutations in AP3B1. Haematologica. 2010; 95:333-337. [PubMed: 19679886]

27. Bohn G, Allroth A, Brandes G, et al. A novel human primary immunodeficiency syndrome caused by deficiency of the endosomal adaptor protein p14. Nat Med. 2007; 13:38-45. [PubMed: 17195838]

28. Bohn G, Hardtke-Wolenski M, Zeidler C, et al. Lethal graft-versus-host disease in congenital neutropenia caused by 14 deficiency after allogeneic bone marrow transplantation from an HLAidentical sibling. Pediatr Blood Cancer. 2008; 51:436-438. [PubMed: 18523989]

29. Sokolic R, Maric I, Kesserwan C, et al. Myeloid dysplasia and bone marrow hypocellularity in adenosine deaminase-deficient severe combined immune deficiency. Blood. 2011; 118:2688-2694. [PubMed: 21725047]

30. Ammann RA, Duppenthaler A, Bux J, Aebi C. Granulocyte colony-stimulating factor-responsive chronic neutropenia in cartilage-hair hypoplasia. J Pediatr Hematol/Oncol. 2004; 26:379-381.

31. Taskinen M, Ranki A, Pukkala E, et al. Extended follow-up of the Finnish cartilage-hair hypoplasia cohort confirms high incidence of non-Hodgkin lymphoma and basal cell carcinoma. Am J Med Genet A. 2008; 146A:2370-2375. [PubMed: 18698627]

32. Guggenheim R, Somech R, Grunebaum E, et al. Bone marrow transplantation for cartilage-hairhypoplasia. Bone Marrow Transplant. 2006; 38:751-756. [PubMed: 17041608]

33. Mäkitie O, Rajantie J, Kaitila I. Anaemia and macrocytosis: unrecognized features in cartilage-hair hypoplasia. Acta Paediatr. 1992; 81:1026-1029. [PubMed: 1290847]

34. Azcona C, Alzina V, Barona P, et al. Use of recombinant human granulocyte-macrophage colony stimulating factor in an infant with reticular dysgenesis. Eur J Pediatr. 1994; 153:164-166. [PubMed: 8181497]

35. Abdollahpour H, Appaswamy G, Kotlarz D, et al. The phenotype of human STK4 deficiency. Blood. 2012; 119:3450-3457. [PubMed: 22294732] This is one of two studies published simultaneously that report the first cases of human $S T K 4$ deficiency.

36. Nehme NT, Schmid JP, Debeurme F, et al. MST1 mutations in autosomal recessive primary immunodeficiency characterized by defective naive T-cell survival. Blood. 2012; 119:3458-3468. [PubMed: 22174160] This is one of two studies published simultaneously that report the first cases of human STK4 deficiency. Three out of four patients were treated with HCT, with one patient surviving the procedure.

37. Hannibal, MC.; Torgerson, T. IPEX syndrome. In: Pagon, RA.; Bird, TD.; Dolan, CR.; Stephens, K.; Adam, MP., editors. Gene Reviews. Seattle: University of Washington; 1993.

38. Zhan H, Sinclair J, Adams S, et al. Immune reconstitution and recovery of FOXP3 (Forkhead Box P3)-expressing T cells after transplantation for IPEX (immune dysregulation, polyendocrinopathy, enteropathy, X-linked) syndrome. Pediatrics. 2008; 121:e998-e1002. [PubMed: 18316354]

39. Baud O, Goulet O, Canioni D, et al. Treatment of the immune dysregulation, polyendocrinopathy, enteropathy, X-linked syndrome (IPEX) by allogeneic bone marrow transplantation. N Engl J Med. 2001; 344:1758-1762. [PubMed: 11396442] 
40. Roy-Ghanta S, Orange JS. Use of cytokine therapy in primary immunodeficiency. Clin Rev Allergy Immunol. 2010; 38:39-53. [PubMed: 19449141]

41. Howard V, Myers LA, Williams DA, et al. Stem cell transplants for patients with X-linked agammaglobulinemia. Clin Immunol. 2003; 107:98-102. [PubMed: 12763478]

42. Notarangelo LD, Rawlings DJ, Sullivan KE. An exemplum of XLA. Clin Immunol. 2008; 126:137-139. [PubMed: 17974484]

43. Levy J, Espanol-Boren T, Thomas C, et al. Clinical spectrum of X-linked hyper-IgM syndrome. J Pediatr. 1997; 131:47-54. [PubMed: 9255191]

44. Rizzi M, Neumann C, Fielding AK, et al. Outcome of allogeneic stem cell transplantation in adults with common variable immunodeficiency. J Allergy Clin Immunol. 2011; 128:1371-1374. e1372. [PubMed: 21930294] This is the first report of allogeneic HCT for common variable immune deficiency. Two patients had hematologic malignancy, and two had severe pulmonary disease. Two patients had acute graft-versus-host disease of the gut, one grade I, one grade III. One patient, who had bronchiectasis prior to transplant, died of hemorrhagic pneumonia.

45. Cham B, Bonilla MA, Winkelstein J. Neutropenia associated with primary immunodeficiency syndromes. Semin Hematol. 2002; 39:107-112. [PubMed: 11957193]

46. Balabanian K, Lagane B, Pablos JL, et al. WHIM syndromes with different genetic anomalies are accounted for by impaired CXCR4 desensitization to CXCL12. Blood. 2005; 105:2449-2457. [PubMed: 15536153]

47. Kriván G, Erdős M, Kállay K, et al. Successful umbilical cord blood stem cell transplantation in a child with WHIM syndrome. Eur J Haematol. 2010; 84:274-275. [PubMed: 19878273]

48. Dale DC, Bolyard AA, Kelley ML, et al. The CXCR4 antagonist plerixafor is a potential therapy for myelokathexis, WHIM syndrome. Blood. 2011; 118:4963-4966. [PubMed: 21835955] This is one of two studies published simultaneously that demonstrate in vivo that plerixafor can increase the neutrophil, monocyte, and lymphocyte counts of patients with WHIM syndrome. This may ultimately lead to improved therapy for the disease.

49. McDermott DH, Liu Q, Ulrick J, et al. The CXCR4 antagonist plerixafor corrects panleukopenia in patients with WHIM syndrome. Blood. 2011; 118:4957-4962. [PubMed: 21890643] This is one of two studies published simultaneously that demonstrate in vivo that plerixafor can increase the neutrophil, monocyte, and lymphocyte counts of patients with WHIM syndrome. This may ultimately lead to improved therapy for the disease.

50. Donadieu J, Bader-Meunier B, Bertrand Y, et al. Recombinant human G-CSF (Lenograstim) for infectious complications in glycogen storage disease type Ib. Report of 7 cases. Nouv Rev Fr Hématol. 1994; 35:529-534. [PubMed: 7512258]

51. Schroten H, Roesler J, Breidenbach T, et al. Granulocyte and granulocyte-macrophage colonystimulating factors for treatment of neutropenia in glycogen storage disease type Ib. J Pediatr. 1991; 119:748-754. [PubMed: 1719175]

52. Pierre G, Chakupurakal G, McKiernan P, et al. Bone marrow transplantation in glycogen storage disease type 1b. J Pediatr. 2008; 152:286-288. [PubMed: 18206704]

53. Rezaei N, Moazzami K, Aghamohammadi A, Klein C. Neutropenia and primary immunodeficiency diseases. Int Rev Immunol. 2009; 28:335-366. [PubMed: 19811314]

54. Kivitie-Kallio S, Rajantie J, Juvonen E, Norio R. Granulocytopenia in Cohen syndrome. Br J Haematol. 1997; 98:308-311. [PubMed: 9266925]

55. Seow WK, Bartold PM, Thong YH, Taylor K. Cohen syndrome with neutropenia-induced periodontitis managed with granulocyte colony-stimulating factor (G-CSF): case reports. Pediatr Dent. 1998; 20:350-354. [PubMed: 9803437]

56. Boerkoel CF, O’Neill S, Andre JL, et al. Manifestations and treatment of Schimke immunoosseous dysplasia: 14 new cases and a review of the literature. Eur J Pediatr. 2000; 159:1-7. [PubMed: 10653321]

57. Petty EM, Yanik GA, Hutchinson RJ, et al. Successful bone marrow transplantation in a patient with Schimke immuno-osseous dysplasia. J Pediatr. 2000; 137:882-886. [PubMed: 11113849]

58. Thomas SE, Hutchinson RJ, DebRoy M, Magee JC. Successful renal transplantation following prior bone marrow transplantation in pediatric patients. Pediatr Transplant. 2004; 8:507-512. [PubMed: 15367289] 
59. Martin CC, Oeser JK, Svitek CA, et al. Identification and characterization of a human cDNA and gene encoding a ubiquitously expressed glucose-6-phosphatase catalytic subunit-related protein. J Mol Endocrinol. 2002; 29:205-222. [PubMed: 12370122]

60. Guionie O, Clottes E, Stafford K, Burchell A. Identification and characterisation of a new human glucose-6-phosphatase isoform. FEBS Lett. 2003; 551:159-164. [PubMed: 12965222]

61. Banka S, Chervinsky E, Newman WG, et al. Further delineation of the phenotype of severe congenital neutropenia type 4 due to mutations in G6PC3. Eur J Hum Genet. 2011; 19:18-22. [PubMed: 20717171] This study adds the clinically important phenotype of venous stasis ulcers to the description of SCN4.

62. Gatti S, Boztug K, Pedini A, et al. A case of syndromic neutropenia and mutation in G6PC3. J Pediatr Hematol/Oncol. 2011; 33:138-140.

63. Cheung YY, Kim SY, Yiu WH, et al. Impaired neutrophil activity and increased susceptibility to bacterial infection in mice lacking glucose-6-phosphatase-beta. J Clin Invest. 2007; 117:784-793. [PubMed: 17318259]

64. Jun HS, Lee YM, Cheung YY, et al. Lack of glucose recycling between endoplasmic reticulum and cytoplasm underlies cellular dysfunction in glucose-6-phosphatase-beta-deficient neutrophils in a congenital neutropenia syndrome. Blood. 2010; 116:2783-2792. [PubMed: 20498302]

65. Jun HS, Lee YM, Song KD, et al. G-CSF improves murine G6PC3-deficient neutrophil function by modulating apoptosis and energy homeostasis. Blood. 2011; 117:3881-3892. [PubMed: 21292774] The authors show that G-CSF not only improves neutropenia in G6pc3-/-mice, but also improves, but does not normalize, respiratory burst, chemotaxis, and calcium flux.

66. Hayee B, Antonopoulos A, Murphy EJ, et al. G6PC3 mutations are associated with a major defect of glycosylation: a novel mechanism for neutrophil dysfunction. Glycobiology. 2011; 21:914-924. [PubMed: 21385794] This report opens a new area of pathophysiology in SCN4 and partially explains the defect in phagocyte oxidase function in the disease.

67. Volpi L, Roversi G, Colombo EA, et al. Targeted next-generation sequencing appoints $c 16$ orf57 as Clericuzio-type poikiloderma with neutropenia gene. Am J Hum Genet. 2010; 86:72-76. [PubMed: 20004881]

68. Colombo EA, Bazan JF, Negri G, et al. Novel C16orf57 mutations in patients with poikiloderma with neutropenia: bioinformatic analysis of the protein and predicted effects of all reported mutations. Orphanet J Rare Dis. 2012; 7:7. [PubMed: 22269211] Using computational analysis, the authors present a hypothetical function for C16orf57, the gene mutated in Clericuzio-type poikiloderma with neutropenia. Previously, this gene had no hypothesized or known function.

69. Walne AJ, Vulliamy T, Beswick R, et al. Mutations in C16orf57 and normal-length telomeres unify a subset of patients with dyskeratosis congenita, poikiloderma with neutropenia and RothmundThomson syndrome. Hum Mol Genet. 2010; 19:4453-4461. [PubMed: 20817924]

70. Wetzler M, Talpaz M, Kleinerman ES, et al. A new familial immunodeficiency disorder characterized by severe neutropenia, a defective marrow release mechanism, and hypogammaglobulinemia. Am J Med. 1990; 89:663-672. [PubMed: 2239986]

71. Hernandez PA, Gorlin RJ, Lukens JN, et al. Mutations in the chemokine receptor gene $C X C R 4$ are associated with WHIM syndrome, a combined immunodeficiency disease. Nat Genet. 2003; 34:70-74. [PubMed: 12692554]

72. McDermott DH, Lopez J, Deng F, et al. AMD3100 is a potent antagonist at CXCR4R334X, a hyperfunctional mutant chemokine receptor and cause of WHIM syndrome. J Cell Mol Med. 2011; 15:2071-2081. [PubMed: 21070597] This in-vitro study demonstrates that plerixafor (AMD3100) ameliorates changes in calcium flux and downstream signaling events in cellular models of WHIM syndrome and in cells from a patient with the syndrome. This study laid the work for clinical study of plerixafor in WHIM syndrome.

73. Kawai T, Malech HL. WHIM syndrome: congenital immune deficiency disease. Curr Opin Hematol. 2009; 16:20-26. [PubMed: 19057201]

74. Liu Q, Chen H, Ojode T, et al. WHIM syndrome caused by a single amino acid substitution in the carboxy-tail of chemokine receptor CXCR4. Blood. 2012; 120:181-189. [PubMed: 22596258] In this study, the authors show that truncation of CXCR4 is not necessary for the phenotypic expression of WHIM syndrome. The patient presented had a missense mutation, but K562 cells 
transfected with a gene coding for the same mutation as that of the patient showed similar effects on CXCR4 downregulation by CXCL12.

75. Doncker AV, Balabanian K, Bellanné-Chantelot C, et al. Two cases of disseminated Mycobacterium avium infection associated with a new immunodeficiency syndrome related to CXCR4 dysfunctions. Clin Microbiol Infect. 2011; 17:135-139. [PubMed: 20148920] The authors present two cases of a potentially novel PIDD with impaired function of CXCR4 after simulation with CXCL12.

76. Balabanian K, Levoye A, Klemm L, et al. Leukocyte analysis from WHIM syndrome patients reveals a pivotal role for GRK3 in CXCR4 signaling. J Clin Invest. 2008; 118:1074-1084. [PubMed: 18274673]

77. Aiuti A, Cattaneo F, Galimberti S, et al. Gene therapy for immunodeficiency due to adenosine deaminase deficiency. N Engl J Med. 2009; 360:447-458. [PubMed: 19179314]

78. Bacigalupo A, Ballen K, Rizzo D, et al. Defining the intensity of conditioning regimens: working definitions. Biol Blood Marrow Transplant. 2009; 15:1628-1633. [PubMed: 19896087]

79. Engel BC, Podsakoff GM, Ireland JL, et al. Prolonged pancytopenia in a gene therapy patient with ADA-deficient SCID and trisomy 8 mosaicism: a case report. Blood. 2007; 109:503-506. [PubMed: 16973956]

80. Sokolic R, Muul L, Garabedian E, et al. Systemic effects of PEG-ADA withdrawal with or without chemotherapy (Chtx) and cytotherapy (CTx) in adenosine deaminase-deficient severe combined immune deficiency (ADA-SCID). J Clin Immunol. 2012; 32:404.

81. Freifeld AG, Bow EJ, Sepkowitz KA, et al. Clinical practice guideline for the use of antimicrobial agents in neutropenic patients with cancer: 2010 update by the Infectious Diseases Society of America. Clin Infect Dis. 2011; 52:e56-e93. [PubMed: 21258094]

82. Schimpff S, Satterlee W, Young VM, Serpick A. Empiric therapy with carbenicillin and gentamicin for febrile patients with cancer and granulocytopenia. N Engl J Med. 1971; 284:1061-1065. [PubMed: 4994878]

83. Fioredda F, Calvillo M, Bonanomi S, et al. Congenital and acquired neutropenia consensus guidelines on diagnosis from the Neutropenia Committee of the Marrow Failure Syndrome Group of the AIEOP (Associazione Italiana Emato-Oncologia Pediatrica). Pediatr Blood Cancer. 2011; 57:10-17. [PubMed: 21448998] These guidelines detail the diagnosis and management of congenital neutropenia.

84. Podjasek JC, Abraham RS. Autoimmune cytopenias in common variable immunodeficiency (CVID). Front Immunol. 2012; 3:189. [PubMed: 22837758]

85. Dale DC, Bonilla MA, Davis MW, et al. A randomized controlled phase III trial of recombinant human granulocyte colony-stimulating factor (filgrastim) for treatment of severe chronic neutropenia. Blood. 1993; 81:2496-2502. [PubMed: 8490166]

86. Rosenberg PS, Alter BP, Bolyard AA, et al. The incidence of leukemia and mortality from sepsis in patients with severe congenital neutropenia receiving long-term G-CSF therapy. Blood. 2006; 107:4628-4635. [PubMed: 16497969]

87. Zeidler C, Welte K. Hematopoietic growth factors for the treatment of inherited cytopenias. Semin Hematol. 2007; 44:133-137. [PubMed: 17631177]

88. Zeidler C, Boxer L, Dale DC, et al. Management of Kostmann syndrome in the G-CSF era. Br J Haematol. 2000; 109:490-495. [PubMed: 10886193]

89. Ward AC, van Aesch YM, Gits J, et al. Novel point mutation in the extracellular domain of the granulocyte colony-stimulating factor (G-CSF) receptor in a case of severe congenital neutropenia hyporesponsive to G-CSF treatment. J Exp Med. 1999; 190:497-508. [PubMed: 10449521]

90. Druhan LJ, Ai J, Massullo P, et al. Novel mechanism of G-CSF refractoriness in patients with severe congenital neutropenia. Blood. 2005; 105:584-591. [PubMed: 15353486]

91. Choi LM, Guelcher C, Guerrera MF. Novel treatment for severe congenital neutropenia with pegfilgrastim. Blood. 2007; 110:4134. [PubMed: 18024801]

92. Draper BK, Robbins JB, Stricklin GP. Bullous Sweet's syndrome in congenital neutropenia: association with pegfilgrastim. J Am Acad Dermatol. 2005; 52:901-905. [PubMed: 15858487]

93. Fioredda F, Calvillo M, Lanciotti M, et al. Pegfilgrastim in children with severe congenital neutropenia. Pediatr Blood Cancer. 2010; 54:465-467. [PubMed: 19927291] 
94. Lähteenmäki PM, Jahnukainen K, Pelliniemi T-T, et al. Severe congenital neutropenia and pegfilgrastim. Eur J Haematol. 2009; 82:75-76. [PubMed: 18774955]

95. Donadieu J, Beaupain B, Rety-Jacob F, Nove-Josserand R. Respiratory distress and sudden death of a patient with GSDIb chronic neutropenia: possible role of pegfilgrastim. Haematologica. 2009; 94:1175-1177. [PubMed: 19644144]

96. Beaupain B, Leblanc T, Reman O, et al. Is pegfilgrastim safe and effective in congenital neutropenia? An analysis of the French Severe Chronic Neutropenia registry. Pediatr Blood Cancer. 2009; 53:1068-1073. [PubMed: 19618456]

97. Buckley, R.; Fischer, A. Bone marrow transplantation for primary immunodeficiency diseases. In: Ochs, H.; Smith, C.; Puck, J., editors. Primary immunodeficiency diseases: a molecular and genetic approach. 2nd. Oxford University Press; 2007. p. 669-687.

98. Small, T.; Friedrich, W.; O'Reilly, R. Hematopoietic cell transplantation for immunodeficiency diseases. In: Appelbaum, F.; Forman, S.; Negrin, R.; Bliume, K., editors. Thomas' hematopoietic cell transplantation. 4th. Wiley-Blackwell; 2009. p. 1105-1124.

99. Buckley RH. Transplantation of hematopoietic stem cells in human severe combined immunodeficiency: longterm outcomes. Immunol Res. 2011; 49:25-43. [PubMed: 21116871] This study describes the long-term outcome of 166 patients with SCID transplanted by Dr Buckley. Donors in this program are primarily haploidentical. The stem cell product is extensively T-cell depleted and neither induction chemotherapy or radiotherapy nor posttransplant immune suppression is used.

100. Gaspar HB, Aiuti A, Porta F, et al. How I treat ADA deficiency. Blood. 2009; 114:3524-3532. [PubMed: 19638621]

101. Aiuti A, Slavin S, Aker M, et al. Correction of ADA-SCID by stem cell gene therapy combined with nonmyeloablative conditioning. Science. 2002; 296:2410-2413. [PubMed: 12089448]

102. Hacein-Bey-Abina S, Le Deist F, Carlier F, et al. Sustained correction of X-linked severe combined immunodeficiency by ex vivo gene therapy. N Engl J Med. 2002; 346:1185-1193. [PubMed: 11961146]

103. Ott MG, Schmidt M, Schwarzwaelder K, et al. Correction of X-linked chronic granulomatous disease by gene therapy, augmented by insertional activation of MDS1-EVI1, PRDM16 or SETBP1. Nat Med. 2006; 12:401-409. [PubMed: 16582916]

104. Boztug K, Dewey RA, Diez IA, et al. Hematopoietic stem cell gene therapy for Wiskott-Aldrich syndrome. Blood. 2007; 110:502.

105. Sokolic R, Podsakoff G, Muul L, et al. Comparative results of gene therapy for adenosine deaminase deficiency with or without PEG-ADA withdrawal and myelosuppressive chemotherapy. Blood. 2007; 110:154a.

106. Kang EM, Choi U, Theobald N, et al. Retrovirus gene therapy for X-linked chronic granulomatous disease can achieve stable long-term correction of oxidase activity in peripheral blood neutrophils. Blood. 2010; 115:783-791. [PubMed: 19965657]

107. Candotti F, Shaw KL, Muul L, et al. Gene therapy for adenosine deaminase-deficient severe combined immune deficiency: clinical comparison of retroviral vectors and treatment plans. Blood. 2012; 120:3635-3646. [PubMed: 22968453]

108. Hacein-Bey-Abina S, von Kalle C, Schmidt M, et al. A serious adverse event after successful gene therapy for X-linked severe combined immunodeficiency. N Engl J Med. 2003; 348:255256. [PubMed: 12529469]

109. Hacein-Bey-Abina S, Von Kalle C, Schmidt M, et al. LMO2-associated clonal T cell proliferation in two patients after gene therapy for SCID-X1. Science. 2003; 302:415-419. [PubMed: 14564000]

110. Stein S, Ott MG, Schultze-Strasser S, et al. Genomic instability and myelodysplasia with monosomy 7 consequent to $E V I 1$ activation after gene therapy for chronic granulomatous disease. Nat Med. 2010; 16:198-204. [PubMed: 20098431] 


\section{KEY POINTS}

- $\quad$ Neutropenia is a feature of several PIDDs, including those of myeloid and lymphoid lineage.

- $\quad$ The pathophysiology, clinical presentation, and management of neutropenia in PIDDs is more varied than in postchemotherapy neutropenia, and requires a more flexible approach.

- $\quad$ The database for managing neutropenia in any given PIDD is sparse, requiring the physician to extrapolate from the postchemotherapy setting.

- $\quad$ Febrile neutropenia is a medical emergency that should be treated by empiric broad-spectrum antibiotics. 


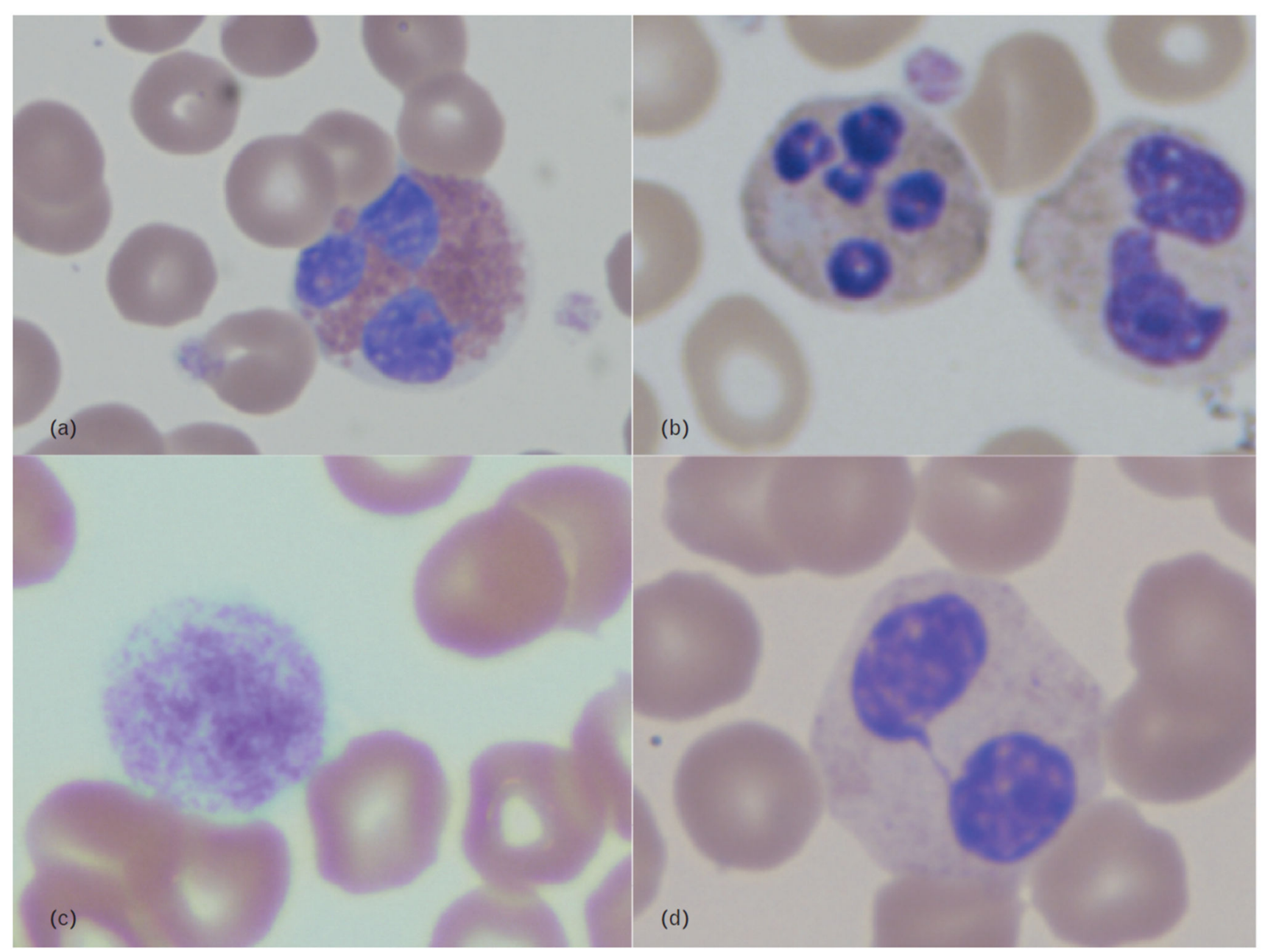

FIGURE 1.

Morphologic abnormalities in the peripheral blood of patients with adenosine deaminase deficient severe combined immunodeficiency: (a) trilobed eosinophil; (b) pyknotic neutrophil; (c) giant platelet, normal red blood cell can be seen next to the platelet for comparison; (d) pseudo-Pelger-Hüet cell. 


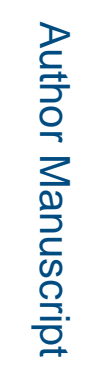

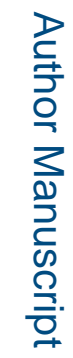

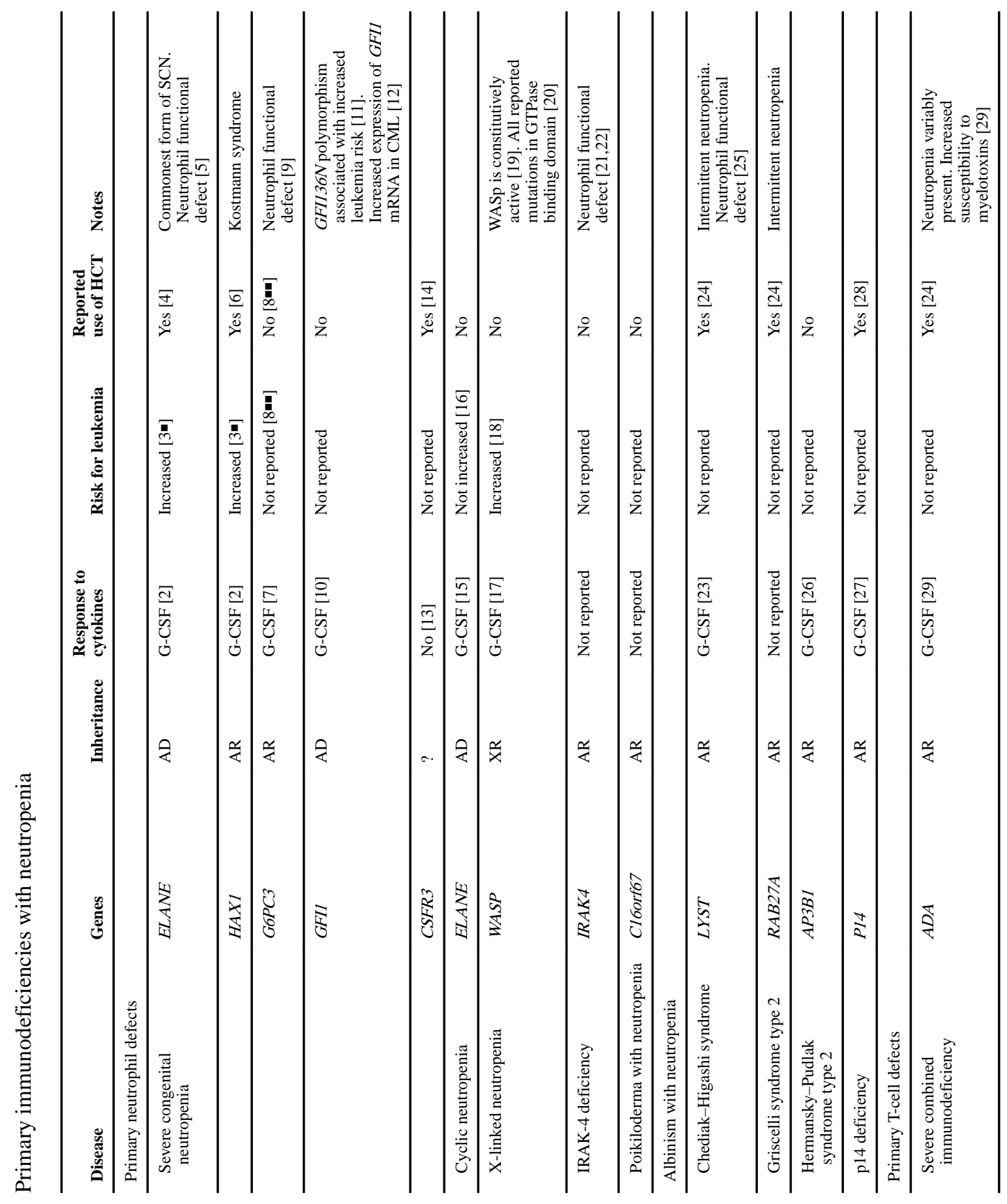

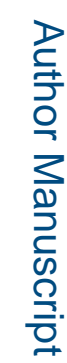

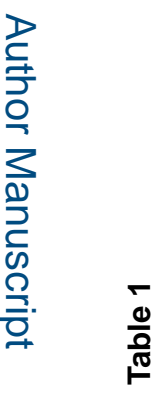

Curr Opin Hematol. Author manuscript; available in PMC 2016 August 26. 


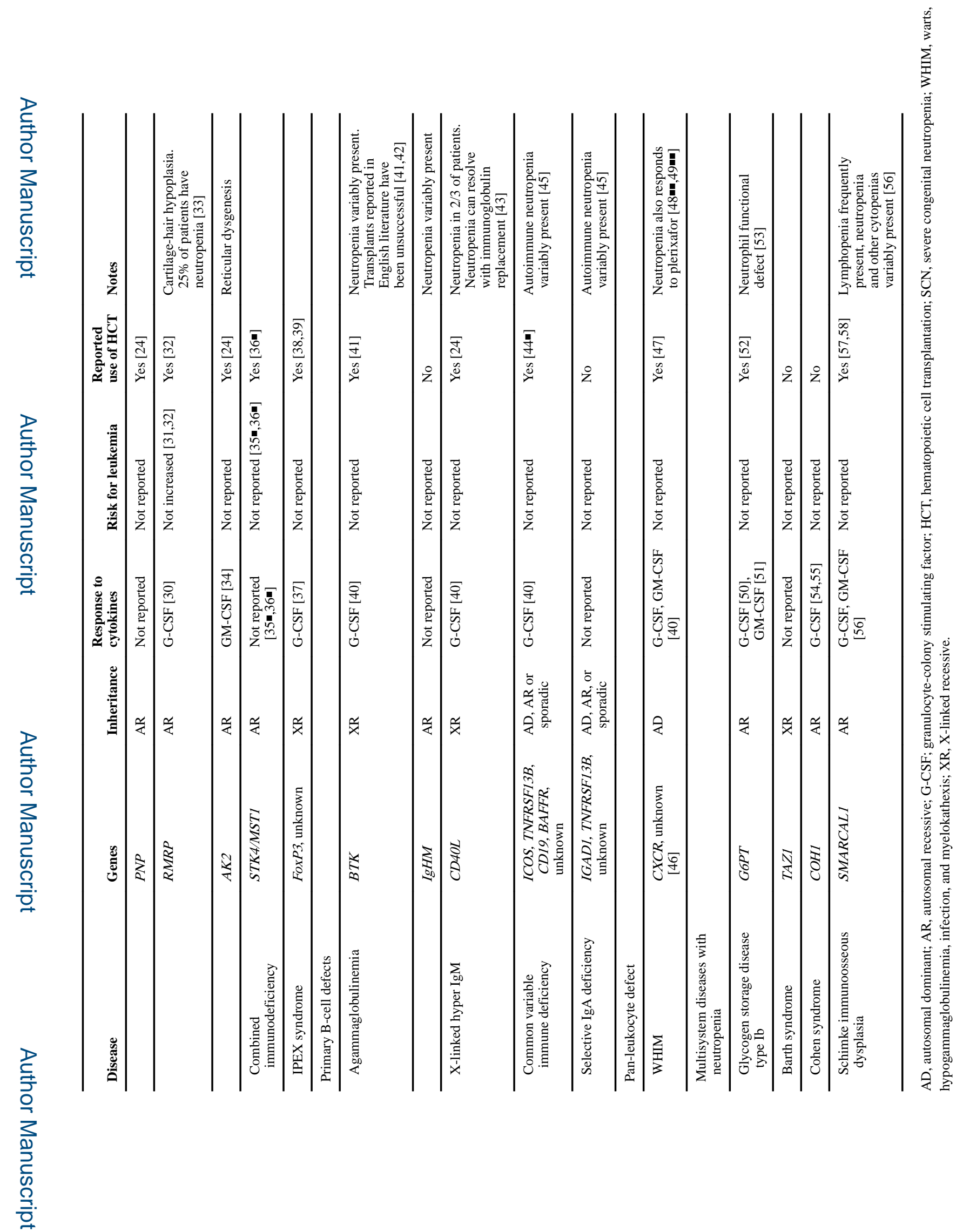

